\title{
RANCANG BANGUN SISTEM INFORMASI GEOGRAFIS PEMETAAN ZONA RUANG RAWAN BENCANA KOTA PALU BERBASIS WEB
}

\author{
Nyongpati Rahmat Tuasikal, Ahmad Faisol, Nurlaily Vendyansyah \\ Program Studi Teknik Informatika S1, Fakultas Teknologi Industri \\ Institut Teknologi Nasional Malang, Jalan Raya Karanglo km 2 Malang, Indonesia \\ 1618123@scholar.itn.ac.id
}

\begin{abstract}
ABSTRAK
Kota Palu merupakan salah satu daerah di wilayah provinsi Sulawesi Tengah yang masuk kategori sangat rawan terjadi bencana seperti gerakan tanah, likuifaksi, sempadan sesar, tsunami dan banjir. Kasus yang paling parah terjadi pada dua tahun silam tepatnya 28 September 2018 dengan terjadinya gempa bumi diikuti dengan tsunami dan likuifaksi tanah. Kurangnya informasi kepada masyarakat untuk membangun bangunan yang sesuai dengan standar SNI.

Pemetaan zona ruang rawan bencana berbasis Sistem Informasi Geografis dibuat menggunakan software QGIS3 untuk pembuatan peta. pembuatan website menggunakan softaware Visual Studio Code, Database menggunakan MySQL, untuk visualisasi wilayah menggunakan geoJSON dan visualisasi peta menggunakan Leaflet. Pemetaan yang akan dibangun untuk sistem informasi geografis yaitu pemetaan zona ruang rawan bencana meliputi data delapan kecamatan dengan zona pengembangan, zona bersyarat, zona terbatas, zona terlarang dan titik-titik bencana. Titik bencana dalam penelitian ini meliputi bencana Gerakan tanah (G), Liquifaksi (L), Sempadan sesar (S), Tsunami (T) dan Banjir (B).

Hasil dari pemetaan zona ruang rawan bencana berbasis web menampilkan peta jenis - jenis bencana dan kategori zona ruang rawan bencana dengan empat klasifikasi yaitu zona terlarang, zona terbatas, zona bersyarat dan zona pengembangan. Dengan adanya website sistem informasi zona ruang rawan bencana akan sangat memudahkan informasi untuk pembangunan bangunan sesuai standar SNI pada Kota Palu .
\end{abstract}

Kata Kunci : SIG, Pemetaan, Zona Ruang Rawan Bencana, Kota Palu, QGIS, Leaflet

\section{PENDAHULUAN}

Indonesia merupakan negara yang sangat rentan terhadap bencana alam dengan berbagai faktor yang mempengaruhi seperti cincin api fasifik dan pertemuan antara tiga lempeng bumi. Sulawesi Tengah, yakni Kota Palu terjadi bencana gempa bumi berkekuatan 7,4 skala richter yang mengakibatkan tsunami dan likuifaksi, gempa bumi ini disebabkan karena Kota Palu berada tepat diatas sesar palu-koro. Bencana alam tersebut menhancurkan bangunan perumahan maupun bangunan pemerintahan bahkan menenggelamkan dan mengubur suatu kawasan seperti yang terjadi di Petobo, Sulawesi Tengah. Maka dari itu pemerintahan membuat zona ruang rawan bencana untuk mempermudah membangun bangunan yang sesuai standar SNI.

Sehubungan dengan hal tersebut, maka disediakan Sistem Informasi Geografis Pemetaan Zona Ruang Rawan Bencana Kota Palu memberikan informasi mengenai jenis-jenis bencana dan daerah dengan area yang rentan terhadap bencana alam berdasarkan tingkatan klasifikasi zona yaitu zona pengembangan, zona bersyarat, zona terbatas dan zona terlarang. Jadi hal ini menyebabkan masyarakat menerima kesalahan informasi dan dapat mengakibatkan pembangunan yang tidak sesuai dengan zona yang telah ditetapkan oleh pemerintah Indonesia. Sehingga sangat membutuhkan Sistem
Informasi Geografis Pemetaan Zona Ruang Rawan Bencana.

Berdasarkan sistem informasi diatas tools yang digunakan adalah aplikasi QGIS untuk pembuatan peta untuk proses menkonversi obyek geografis dari peta raster ke vektor dengan menambahkan atribut yang beriskan informasi dari peta yang dibuat. Kemudian Peta yang telah dibuat akan disimpan menggunakan file berekstensi geojson untuk memvisulisasikan peta kedalam web menggunakan leaflet perpustakaan javascript open source.

Oleh karena itu untuk mendukung pemerintahan Kota Palu dalam penyampaian informasi zona ruang rawan bencan perlu di kembangkan suatu system yang memaksimalkan pemetaan zona ruang rawan bencana Kota Palu. Dengan pemetaan zona ruang rawan bencana Kota Palu berbasi web mempermudah akses informasi secara akurat.

\section{TINJAUAN PUSTAKA}

\subsection{Penelitian Terdahulu}

Pada tahun 2014 Hamdani dan kawan-kawan menganallisa daerah rawan banjir menggunakan aplikasi sistem informasi geografis (studi kasus pulau bangka) dengan 3 parameter yaitu (1) curah hujan, (2) kelerengan dan (3) penggunaan lahan. Hasil analisa semua parameter dibandingkan dan diberi bobot menggunakan metode Analytic Hierarchy Process (AHP) matriks Pairwise Comparison. Diperoleh nilai 
bobot untuk penggunaan lahan adalah 0,87 , hujan 0,27 dan kelerengan 0,08. Seluruh hasil analisa digabung menggunakan metode Overlay Intersection pada ArcGIS10.1 untuk menghasilkan peta daerah rawan banjir berdasarkan 3 parameter yang digunakan. [1]

Ditahun 2016 Wibowo dan kawan-kawan membuat aplikasi aplikasi pemetaan berbasis website untuk pusat kesehatan masyarakat di wilayah kabupaten malang. Semakin pesatnya perkembangan teknologi di zaman ini, menjadikan peta konvensional terlihat sudah tidak layak digunakan alias ketinggalan zaman jika dibandingkan dengan peta digital yang sangat efisien. Seringkali mengalami hambatan untuk mengakses kesehatan karena kendala medan, komunikasi bahkan transportasi sehingga permasalahan itu menjadi isu penting. Oleh karena itu diperlukan sistem informasi geografis untuk memetakan pusat kesehatan masyarakat khususnya di wilayah kabupaten malang secara efektif dan efisien dengan perangkat lunak yang ada. [2]

Sistem monitoring untuk kawasan rawan banjir berbasis arduino. Banjir merupakan masalah yang sangat sering terjadi di indonesia disaat musim penghujan tiba. Maka penanganan banjir perlu ditangani denngan serius karena membahayakan. Dengan kemajuan saat ini kita seharusnya dapat memanfaatkannya untuk memperingati adanya bencana alam seperti banjir lebih dini, yakni dengan menggunakan IOT (Internet of things). . Dengan menggunakan Internet of Thinks dapat mempermudah dan efesien untuk momonitoring suatu kawasan yang rawan terkena banjir. [3]

Sistem informasi geografis penggunaan lahan dan produksi tanaman pangan pada dinas pertanian Kabupaten Kediri sebagai sarana untuk memudahkan dalam mendapatkan informasi. Untuk saat ini Dinas Pertanian dan Perkebunan Kabupaten Kediri masih mengalami kesulitan memantau pertanian di Kabupaten Kediri karena luasnya wilayah dan belum ada sistem yang dapat membantu pendataan lahan pertanian dan hasil produksi tanaman pangan. Sehingga pada pembuatan sistem informasi ini diharapkan dapat memetakan dan menganalisis dari berbagai ragam hasil pertanian di beberapa kecamatan di Kabupaten Kediri. [4]

Sistem infomasi geografis pemetaan daerah perkebunan dan komoditas hasil panen provinsi Kalimantan Tengah. Dengan penyajian data dan potensi komoditi perkebunan saat ini masih banyak disajikan dalam bentuk statistik. Untuk mengatasi masalah tersebut maka perlu dikembangkan suatu sistem yang memaksimalkan pemetaan tiap tanah berdasarkan komoditas hasil panen di provinsi Kalimantan Tenngah. [5]

\subsection{Dasar Teori}

\subsubsection{Sistem Informasi Geografis}

Sistem Informasi Geografis (SIG) atau Geographic Information System (GIS) adalah sebuah sistem yang didesain untuk menangkap, menyimpan, memanipulasi, menganalisa, mengatur dan menampilkan seluruh jenis data geografis. Sistem Informasi Geografis merupakan sistem pemetaan peta yang dibuat untuk memudahkan admin pada proses mengolah data dan menampilkan informasi kepada user berdasarkan data yang akurat. [6]

\subsubsection{QGIS}

Quantum GIS (QGIS) adalah sebuah aplikasi Geographical Information System (GIS) sumber terbuka dan lintas platform yang dapat dijalankan di sejumlah sistem operasi termasuk Linux. QGIS juga memiliki kemampuan untuk bekerjasama dengan paket aplikasi komersil terkait. QGIS menyediakan semua fungsionalitas dan fitur-fitur yang dibutuhkan oleh pengguna GIS pada umumnya. Menggunakan plugins dan fitur inti (core features) dimungkinkan untuk menvisualisasi (meragakan) pemetaan (maps) untuk kemudian diedit dan dicetak sebagai sebuah peta yang lengkap. Penguna dapat menggabungkan data yang dimiliki untuk dianalisa, diedit dan dikelola sesuai dengan apa yang diinginkan. [7]

\subsubsection{Leaflet}

Leaflet adalah perpustakaan JavaScript open source terkemuka untuk peta interaktif yang ramah. Fitur pemetaan yang disediakan sangat banyak guna mendukung kebutuhan pengemabang. Leaflet dirancang dengan kesederhanaan kinerja dan kegunaan dalam pikiran, mampu bekerja secara efisien disemua platform desktop dan seluler utama, dapat diperluas dengan plugin, memiliki API yang indah, mudah digunakan, dan terdokumentasi serta kode sumber yang mudah dibaca dan menyenangkan. Leaflet memberikan peta secara terbuka yang dapat diambil dengan mudah oleh pengembang merancang sebuah pemetaan wilayah. [8]

\subsubsection{Pemetaan Zona Ruang Rawan Bencana}

Kesadaran akan keterkaitan antara bencana alam dan penataan ruang telah disadari oleh pembentuk Undang-Undang No. 26 Tahun 2007 tentang Penataan Ruang (UUTR). Dalam salah satu pertimbangannya disebutkan bahwa Negara Kesatuan Republik Indonesia berada pada kawasan rawan bencana sehingga diperlukan penataan ruang yang berbasis mitigasi bencana sebagai upaya meningkatkan keselamatan dan kenyamanan kehidupan dan penghidupan. Dalam Penjelasan Umum diuraikan bahwa selain letaknya yang strategis, Indonesia berada pula pada kawasan rawan bencana, yang secara alamiah dapat mengancam keselamatan bangsa. Dalam Peraturan Pemerintah No. 15 Tahun 2010 tentang penyelenggaraan penataan ruang (PPTR), dijelaskan lebih spesifik bahwa Indonesia terletak pada kawasan pertemuan 3 (tiga) lempeng tektonik yang mengakibatkan rawan bencana geologi sehingga menuntut prioritisasi pertimbangan aspek mitigasi bencana. [9] 


\section{METODE PENELITIAN}

\subsection{Analisis Kebutuhan Fungsional}

Kebutuhan fungsional adalah salah satu kebutuhan sistem dalam menyajikan fitur-fitur apa saja yang terdapat pada sebuah sistem.

1. Sistem dapat melakukan proses login dan logout.

2. Sistem dapat menampilkan informasi data bencana yang terjadi di Kota Palu.

3. Sistem dapat menampilkan informasi zona bencana untuk arahan spasial pemanfaatan ruang.

4. Sistem dapat memberikan informasi mengenai website yang dibangun serta pengetahuan tentang bencana alam kepada user.

5. Sistem dapat menampilkan Peta Kota dengan tiaptiap kecamatan.

6. Sistem dapat menampilkan peta zona ruang rawan bencana berdasarkan gradasi warna untuk empat klasifikasi zona yaitu zona pengembangan, zona bersyarat, zona terbatas dan zona terlarang.

7. Sistem dapat memberikan detail informasi zona ruang rawan bencana, titik bencana titik bencana seperti gerakan tanah $(\mathrm{G})$, liquifaksi (L), sempadan sesar (S), tsunami (T) dan banjir (B) yang terdapat pada delapan kecamatan Kota Palu.

8. Sistem dapat memberikan informasi berupa grafik untuk jumlah titik bencana berdasarkan tiap-tiap kecamatan Kota Palu.

9. Sistem dapat menampilkan peta dalam mode grayscale serta dapat melakukan zoom in dan zoom out.

10. Sistem dapat memberikan layanan pengolahan data jenis bencana dan zona dan tipologi kepada admin untuk dapat melakukan tambah data, edit dan hapus data.

\subsection{Anaslisi Kebutuhan Non Fungsional}

Kebutuhan non-funsional adalah salah satu kebutuhan dalam proses pembuatan maupun dalam proses saat menjalankan sebuah sistem tersebut. Dimana kebutuhan tersebut yang terdiri dari perangkat dan sumberdaya yang dibutuhkan oleh sistem, diantaranya yaitu :

1. Perangkat Keras (Hardware)

Untuk membuat Sistem Informi Geografis Pemetaan Zona Ruang Rawan Bencana Kota Palu adalah menggunakan Lenovo 100-14ibd 80RK dengan spesifikasi sebagai berikut :
a. Prosesor
: Intel $\mathbb{R}$ Core ${ }^{\mathrm{TM}} \mathrm{i} 3-5005 \mathrm{U}$
b. Memory
: $10 \mathrm{~GB}$ DDR3
c. HDD
: $500 \mathrm{~GB}$
d. VGA
e. Mouse
: Intel® HD Graphics 5500

2. Perangkat Lunak (Software)
a. Sistem Operasi Windows 1064 bit
b. Quantum GIS
c. Xampp v.3.2.3
d. Visual Studio Code
e. Google Chrome

\subsection{Perancangan Sistem}

Adapaun desain dalam pembangunan sistem informasi geografis dapat dilihat pada Gambar 1.

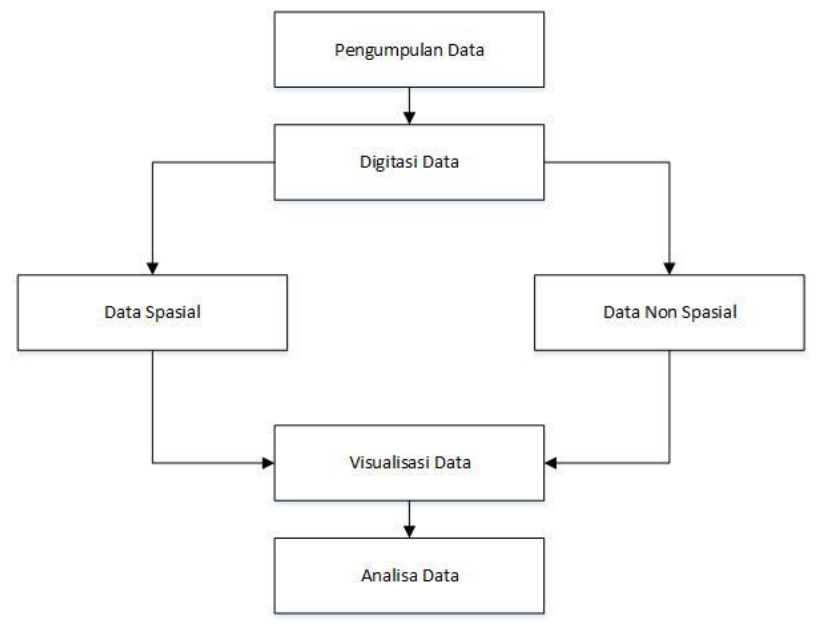

Gambar 1. Desain Proses

Penjelasan pada Gambar 1 :

Data Terkumpul : data yang digunakan adalah data

Kota Palu.

Digitasi : proses pre-processing terhadap data sehingga menjadi sebuah peta berkestensi geojson.

Visualisasi : output yang akan di tampilkan di website.

Analisa : dilakukan analisa manual dari hasil output.

\subsection{Desain Arsitektur Sistem}

Desain arsitektur sistem merupakan salah satu perancangan sistem. Pada perancangan ini menggabarkan suatu kinerja dari sistem yang dibuat secara keseluruhan ketika terdapat aktivitas yang dilakukan oleh pengguna serta menggambarkan komponen dari setiap sistem. Desain arsitektur sistem ini terdiri dari 3 layer yang dimana setiap layer yaitu client layer, service layer dan support layer. Berikut desain arsitektur sistem yang terlihat seperti pada Gambar 2.

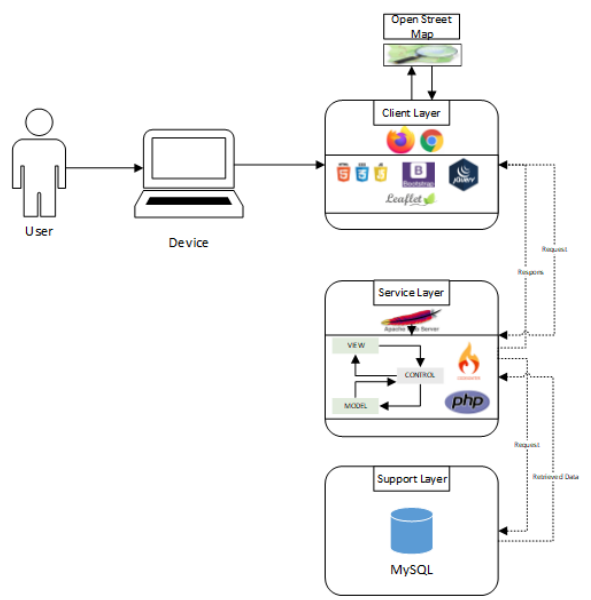

Gambar 2 Desain Arsitektur Sistem 


\subsection{Flowchart Sistem}

Pada tahap ini, sistem informasi geografis zona ruang rawan bencana akan menunjukkan diagram alir prosedur sistem, seperti yang ditunjukkan pada Gambar 3.

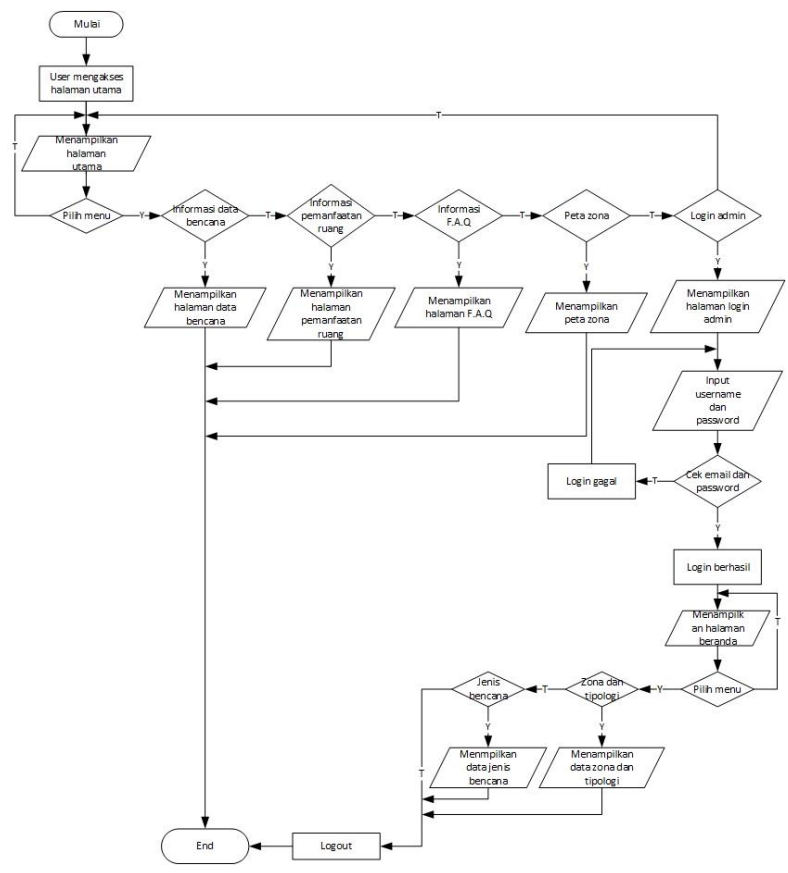

Gambar 3. Flowchart Sistem

Pada gambar 3 dimulai dengan user mengakses halaman utama selanjutnya web menampilkan halaman beranda untuk user kemudian pada pilihan menu terdapata beberapa menu diantaranya menu informasi data bencana jika dipilih menu informasi data bencana maka website akan menampilkan informasi halaman data bencana, jika tidak maka ke menu selanjutnya tentang informasi pemanfaatan ruang kemudian website akan menampilkan halaman informasi pemanfaatan ruang, jika tidak maka ke menu selanjutnya tentang informasi f.a.q kemudian website menampilkan halaman informasi f.a.q, jika tidak maka ke menu selanjutnya tentang peta zona kemudian website akan menampilkan halaman peta zona ruang rawn bencana Kota Palu, jika tidak maka akan ke menu selanjutnya yaitu menu login untuk admin. Website akan menampilkan halaman login admin, kemudian admin menginput username dan password akan di cek email dan password jika tidak maka login gagal dan akan kembali menampilkan halaman login admin, jika ya maka login berhasil kemudian akan dialihkan ke halaman dashboard admin. Selanjutnya ke pemilihan menu zona dan tiplogi maka akan menampilkan data zona dan tipologi jika tidak ke menu selanjutnya yaitu menu jenis bencana akan menampilkan data jenis bencana kemudian jika tidak maka akan ke proses logout dan program end.

\subsection{Titik Bencana Pada Peta}

Titik bencana pada peta merupakan zona pengembangan(1), zona bersyarat(2), zona terbatas(3), zona terlarang(4), dan titik bencana seperti gerakan tanah (G), liquifaksi (L), sempadan sesar (S), tsunami (T) dan banjir (B). Dengan data yang dapat memberikan informasi berdasarkan sistem yang di buat seperti pada Tabel 1.

Tabel 1. Titik Bencana

\begin{tabular}{|c|c|c|c|}
\hline $\begin{array}{l}\text { Tingkat } \\
\text { Bencana }\end{array}$ & Zona & Label & Bencana \\
\hline \multirow{5}{*}{1} & \multirow{5}{*}{ Pengembangan } & G & $\begin{array}{l}\text { Gerakan } \\
\text { tanah }\end{array}$ \\
\hline & & B & Banjir \\
\hline & & $\mathrm{L}$ & Liquifaksi \\
\hline & & $\mathrm{T}$ & Tsunami \\
\hline & & $\mathrm{S}$ & $\begin{array}{l}\text { Sempadan } \\
\text { sesar }\end{array}$ \\
\hline \multirow{5}{*}{2} & \multirow{5}{*}{ Bersyarat } & G & $\begin{array}{l}\text { Gerakan } \\
\text { tanah }\end{array}$ \\
\hline & & B & Banjir \\
\hline & & $\mathrm{L}$ & Liquifaksi \\
\hline & & $\mathrm{T}$ & Tsunami \\
\hline & & S & $\begin{array}{l}\text { Sempadan } \\
\text { sesar }\end{array}$ \\
\hline \multirow{5}{*}{3} & \multirow{5}{*}{ Terbatas } & G & $\begin{array}{l}\text { Gerakan } \\
\text { tanah }\end{array}$ \\
\hline & & B & Banjir \\
\hline & & $\mathrm{L}$ & Liquifaksi \\
\hline & & $\mathrm{T}$ & Tsunami \\
\hline & & $\mathrm{S}$ & $\begin{array}{l}\text { Sempadan } \\
\text { sesar }\end{array}$ \\
\hline \multirow{5}{*}{4} & \multirow{5}{*}{ Terlarang } & G & $\begin{array}{l}\text { Gerakan } \\
\text { tanah }\end{array}$ \\
\hline & & B & Banjir \\
\hline & & $\mathrm{L}$ & Liquifaksi \\
\hline & & $\mathrm{T}$ & Tsunami \\
\hline & & S & $\begin{array}{l}\text { Sempadan } \\
\text { sesar }\end{array}$ \\
\hline
\end{tabular}

Pada Tabel 1. menjelaskan tentang titik-titik bencana yang di tampilkan pada sistem berdasarkan zona pengembangan untuk tingkat bencana 1 , zona bersyarat untuk tingkat bencana 2, zona terbatas untuk tingkat bencana 3 , zona terlarang untuk tingkat bencana 4 .

\subsection{Perancangan Database}

\subsubsection{Tabel Admin}

Tabel Admin merupakan tabel yang digunakan untuk menyimpan informasi dari user yang mengolah data dari Sistem Informasi Geografis Pemetaan Zona Ruang Rawan Bencana Kota Palu dan Sekitsrnya. Deskripsi tabel dapat dilihat pada Tabel 2. 
Tabel 2. Struktur Tabel Admin

\begin{tabular}{|c|c|c|c|l|}
\hline No. & $\begin{array}{c}\text { Nama } \\
\text { Field }\end{array}$ & $\begin{array}{c}\text { Tipe } \\
\text { Data }\end{array}$ & Ukuran & \multicolumn{1}{|c|}{ Keterangan } \\
\hline 1. & id & Int & 8 & $\begin{array}{l}\text { Not Null, } \\
\text { Primary Key, } \\
\text { Auto Increment }\end{array}$ \\
\hline 2. & email & Varchar & 255 & Not Null \\
\hline 3. & pass & varchar & 255 & Not Null \\
\hline
\end{tabular}

\subsubsection{Tabel Data Bencana}

Tabel ini berfungsi untuk menyimpan data jenisjenis bencana. Deskripsi tabel dapat dilihat pada Tabel 3.

Tabel 3. Tabel Data Bencana

\begin{tabular}{|c|c|c|c|c|}
\hline No. & Nama Field & $\begin{array}{c}\text { Tipe } \\
\text { Data }\end{array}$ & Ukuran & Keterangan \\
\hline 1. & Jenis_bencana & Varchar & 100 & Not Null \\
\hline 2. & label & Varchar & 100 & Not Null \\
\hline
\end{tabular}

\subsubsection{Tabel Zona}

Tabel ini berfungsi untuk menyimpan data zona, definis/kriteria dan arahan spasial untuk pembangunan. Deskripsi tabel dapat dilihat pada Tabel 4.

Tabel 4. Tabel Data Zona

\begin{tabular}{|c|c|c|c|c|}
\hline No. & Nama Field & $\begin{array}{c}\text { Tipe } \\
\text { Data }\end{array}$ & Ukuran & Keterangan \\
\hline 1. & zonatipologi & Varchar & 8 & Not Null \\
\hline 2. & kriteria & Text & & Not Null \\
\hline 3. & arahanspasial & Text & & Not Null \\
\hline
\end{tabular}

\section{HASIL DAN PEMBAHASAN}

\subsection{Halaman Login}

Tampilan dari halaman login dimana admin harus memasukan password dan username agar masuk ke halaman admin.

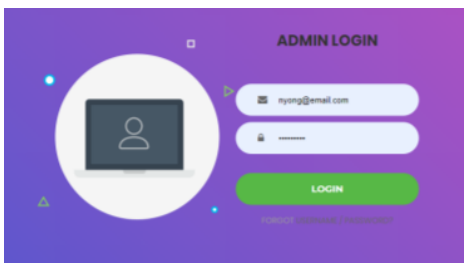

Gambar 4. Halaman login admin

\subsection{Halaman input data jenis bencana}

Halaman form input data jenis bencana digunakan untuk melakukan penambahan data atau pengeditan data-data yang kemudian akan di tampilkan di website.

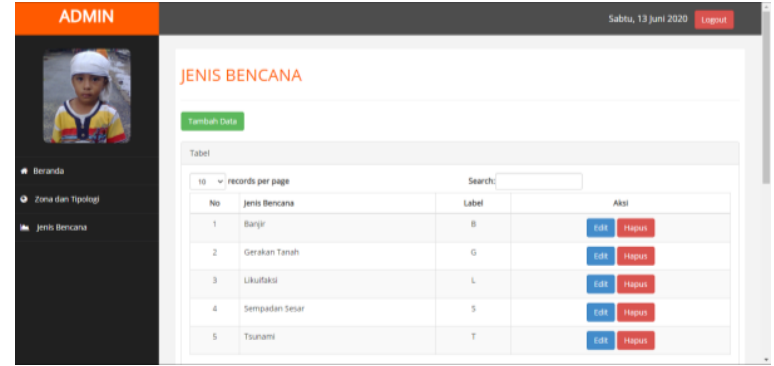

Gambar 5. Form input data

\subsection{Halaman zona dan tipologi}

Halaman informasi berdasarkan klasifikasi zona dengan kriteria dan arahan spasial pasca bencana.

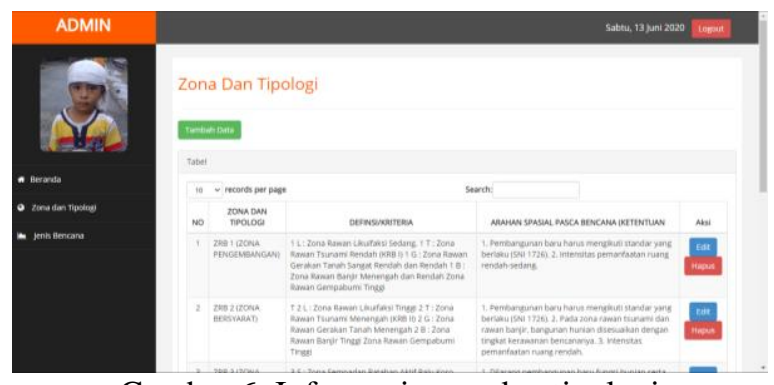

Gambar 6. Informasi zona dan tipologi

\subsection{Halaman peta zona ruang rawan bencana}

Tampilan halaman peta pemetaan zona rung rawan bencana kota palu berdasarakan klasifikasi warna dengan legenda untuk menampilkan checkbox pada tiap layer kecamatan dan informasi mengenai jenis bencana dan populasi.

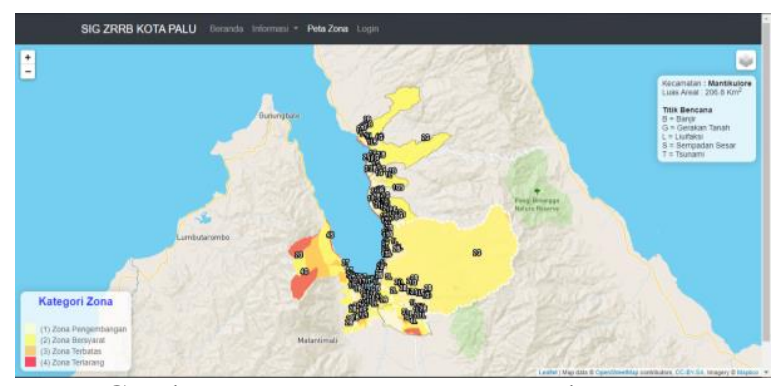

Gambar 7. Peta zona rung rawan bencana

\subsection{Chart}

Tampilan chart merupakan konklusi jumlah titik-titik bencana pada delapan kecamatan di Kota Palu berdasarkan jenis-jenis bencana seperti banjir, gerakan tanah, liquifaksi, sempadan sesar, dan tsunami. 


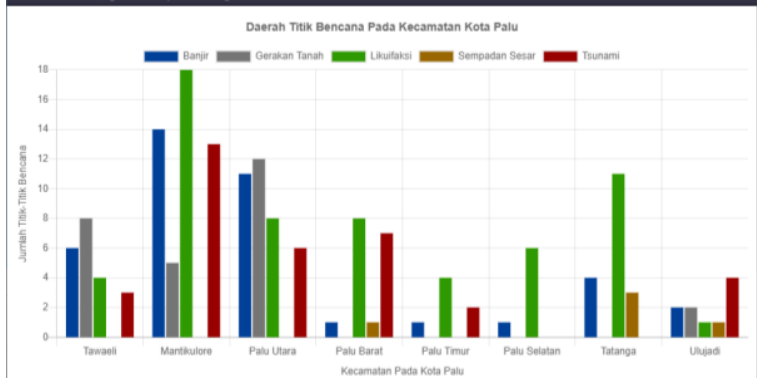

Gambar 8. Tampilan grafik jumlah titik bencana

\subsection{Pengujian Black-Box}

Pengujian sistem merupakan proses menampilkan sistem dengan maksud untuk menemukan adanya kesalahan atau tidak pada sistem sebelum sistem dipublikasikan untuk digunakan oleh masyarakat. Hasil pengujian sistem ditunjuak kan pada Tabel 4. sebagai berikut.

Tabel 4. Pengujian Black-Box user

\begin{tabular}{|c|c|c|c|}
\hline Butir uji & $\begin{array}{l}\text { Hasil yang } \\
\text { diharapkan }\end{array}$ & Hasil sebenarnya & Hasil \\
\hline $\begin{array}{l}\text { Halaman } \\
\text { tampilan } \\
\text { beranda }\end{array}$ & $\begin{array}{l}\text { Menampilkan } \\
\text { halaman } \\
\text { beranda }\end{array}$ & $\begin{array}{l}\text { Dapat menampilkan } \\
\text { informasi pada } \\
\text { halaman utama saat } \\
\text { pertama kali akses } \\
\text { web sistem informasi } \\
\text { geografis zona ruang } \\
\text { rawan bencana }\end{array}$ & Sesuai \\
\hline $\begin{array}{l}\text { Halaman } \\
\text { tampilan } \\
\text { informmasi } \\
\text { data } \\
\text { bencana }\end{array}$ & $\begin{array}{l}\text { Menampilkan } \\
\text { informasi data } \\
\text { bencana }\end{array}$ & $\begin{array}{c}\text { Dapat menampilkan } \\
\text { informasi tentang data } \\
\text { bencana zona ruang } \\
\text { rawan bencana pada } \\
\text { Kota Palu. }\end{array}$ & Sesuai \\
\hline $\begin{array}{l}\text { Halaman } \\
\text { tampilan } \\
\text { informasi } \\
\text { pemanfaata } \\
\text { n ruang }\end{array}$ & $\begin{array}{l}\text { Menampilkan } \\
\text { informasi } \\
\text { pemanfaatan } \\
\text { ruang }\end{array}$ & $\begin{array}{l}\text { Dapat menampilkan } \\
\text { informasi pemanfaatan } \\
\text { ruang untuk } \\
\text { mengetahui zonasi } \\
\text { yang tepat untuk } \\
\text { pembangunan }\end{array}$ & Sesuai \\
\hline $\begin{array}{l}\text { Halaman } \\
\text { tampilan } \\
\text { f.a.q }\end{array}$ & $\begin{array}{l}\text { Menampilkan } \\
\text { informasi f.a.q }\end{array}$ & $\begin{array}{l}\text { Dapat menampilkan } \\
\text { pertanyaan dengan } \\
\text { jawaban untuk } \\
\text { memudahkan user } \\
\text { dalam memahami } \\
\text { sistem }\end{array}$ & Sesuai \\
\hline $\begin{array}{l}\text { Halaman } \\
\text { tampilan } \\
\text { peta zona }\end{array}$ & $\begin{array}{l}\text { Menampilkan } \\
\text { peta zona } \\
\text { ruang rawan } \\
\text { bencana Kota } \\
\text { Palu }\end{array}$ & $\begin{array}{l}\text { Dapat menampilkan } \\
\text { peta zona ruang rawan } \\
\text { bencana Kota Palu }\end{array}$ & Sesuai \\
\hline $\begin{array}{l}\text { Halaman } \\
\text { tampilan } \\
\text { chart }\end{array}$ & $\begin{array}{l}\text { Menampilkan } \\
\text { hasil konklusi } \\
\text { dari jumlah titik } \\
\text { bencana tiap } \\
\text { kecamatan }\end{array}$ & $\begin{array}{c}\text { Dapat menampilkan } \\
\text { grafik cahart jumlah } \\
\text { bencana tiap } \\
\text { kecamatan }\end{array}$ & Sesuai \\
\hline $\begin{array}{l}\text { Fitur zoom } \\
\text { in dan zoom } \\
\text { out } \\
\text { tampilan } \\
\text { peta } \\
\end{array}$ & $\begin{array}{l}\text { Memperbesar } \\
\text { dan } \\
\text { memperkecil } \\
\text { tampilan peta }\end{array}$ & $\begin{array}{l}\text { Dapat meperbesar dan } \\
\text { memperkecil tampilan } \\
\text { peta }\end{array}$ & Sesuai \\
\hline $\begin{array}{l}\text { Informasi } \\
\text { data pada } \\
\text { setiap } \\
\text { kecamatan, } \\
\text { zona ruang } \\
\text { rawan } \\
\text { bencana } \\
\text { dan titik } \\
\text { bencana }\end{array}$ & $\begin{array}{l}\text { Menampilkan } \\
\text { informasi } \\
\text { kecamatan, } \\
\text { zona ruang } \\
\text { rawan bencana, } \\
\text { dan titik } \\
\text { bencana }\end{array}$ & $\begin{array}{l}\text { Dapat menampilkan } \\
\text { informasi data pada } \\
\text { saat mengklik titik } \\
\text { bencana dan } \\
\text { mengarahkan kursor } \\
\text { pada peta }\end{array}$ & Sesuai \\
\hline
\end{tabular}

\begin{tabular}{|c|c|c|c|}
\hline Butir uji & $\begin{array}{c}\text { Hasil yang } \\
\text { diharapkan }\end{array}$ & Hasil sebenarnya & Hasil \\
\hline $\begin{array}{c}\text { grayscale } \\
\text { peta }\end{array}$ & $\begin{array}{c}\text { Menampilkan } \\
\text { peta hitam } \\
\text { puth }\end{array}$ & $\begin{array}{c}\text { Dapat menampilkan } \\
\text { peta dengan warna } \\
\text { hitam putih }\end{array}$ & Sesuai \\
\hline $\begin{array}{c}\text { Checkbox } \\
\text { layer }\end{array}$ & $\begin{array}{c}\text { Menampilkan } \\
\text { checkbox pada } \\
\text { layer grup }\end{array}$ & $\begin{array}{c}\text { Dapat menampilkan } \\
\text { dan menghilangkan } \\
\text { checkbox tiap layer } \\
\text { pada tiap kecamatan, } \\
\text { titik bencana dan zona } \\
\text { bencana }\end{array}$ & Sesuai \\
\hline
\end{tabular}

Tabel 5. Pengujian Black-Box Admin

\begin{tabular}{|c|c|c|c|}
\hline Butir uji & $\begin{array}{c}\text { Hasil yang } \\
\text { diharapkan }\end{array}$ & Hasil sebenarnya & Hasil \\
\hline $\begin{array}{l}\text { Login } \\
\text { Admin }\end{array}$ & $\begin{array}{l}\text { Verifikasi } \\
\text { username dan } \\
\text { password }\end{array}$ & $\begin{array}{l}\text { Dapat mengisi data } \\
\text { login sesuai yang } \\
\text { diharapkan }\end{array}$ & Sesuai \\
\hline $\begin{array}{l}\text { Halaman } \\
\text { data jenis } \\
\text { bencana }\end{array}$ & $\begin{array}{c}\text { Menampilkan } \\
\text { data yang } \\
\text { telah } \\
\text { dimasukkan } \\
\text { atau data } \\
\text { yang ada di } \\
\text { database }\end{array}$ & $\begin{array}{l}\text { Menampilkan data } \\
\text { pada halaman data } \\
\text { jenis bencana }\end{array}$ & Sesuai \\
\hline $\begin{array}{l}\text { Halaman } \\
\text { input data } \\
\text { jenis } \\
\text { bencana }\end{array}$ & $\begin{array}{l}\text { Memasukkan } \\
\text { data jenis } \\
\text { bencana dan } \\
\text { data jenis } \\
\text { bencana } \\
\text { tersebut } \\
\text { tersimpan di } \\
\text { database }\end{array}$ & $\begin{array}{c}\text { Data berhasil di } \\
\text { tambahkan di database }\end{array}$ & Sesuai \\
\hline $\begin{array}{l}\text { Halaman } \\
\text { edit data } \\
\text { jenis } \\
\text { bencana }\end{array}$ & $\begin{array}{c}\text { Mengubah } \\
\text { data jenis } \\
\text { bencana yang } \\
\text { sudah ada di } \\
\text { dalam } \\
\text { database }\end{array}$ & $\begin{array}{c}\text { Data berhasil di edit } \\
\text { dan disimpan di } \\
\text { database }\end{array}$ & Sesuai \\
\hline $\begin{array}{l}\text { Halaman } \\
\text { hapus data } \\
\text { jenis } \\
\text { bencana }\end{array}$ & $\begin{array}{c}\text { Menghapus } \\
\text { data jenis } \\
\text { bencana di } \\
\text { dalam } \\
\text { database }\end{array}$ & $\begin{array}{l}\text { Data berhasil di hapus } \\
\text { di dalam database }\end{array}$ & Sesuai \\
\hline $\begin{array}{l}\text { Halaman } \\
\text { data zona } \\
\text { dan tipologi }\end{array}$ & $\begin{array}{l}\text { Menampilkan } \\
\text { data yang } \\
\text { telah } \\
\text { dimasukkan } \\
\text { atau data } \\
\text { yang ada di } \\
\text { database }\end{array}$ & $\begin{array}{l}\text { Menampilkan data } \\
\text { pada halaman data } \\
\text { zona dan tipologi }\end{array}$ & Sesuai \\
\hline $\begin{array}{l}\text { Halaman } \\
\text { input data } \\
\text { zona dan } \\
\text { tipologi }\end{array}$ & $\begin{array}{l}\text { Memasukkan } \\
\text { data zona dan } \\
\text { tipologi dan } \\
\text { data zona dan } \\
\text { tipologi } \\
\text { tersebut } \\
\text { tersimpan di } \\
\text { database }\end{array}$ & $\begin{array}{c}\text { Data berhasil di } \\
\text { tambahkan di database }\end{array}$ & Sesuai \\
\hline $\begin{array}{l}\text { Halaman } \\
\text { edit data } \\
\text { zona dan } \\
\text { tipologi }\end{array}$ & $\begin{array}{c}\text { Mengubah } \\
\text { data zona dan } \\
\text { tipologi yang } \\
\text { sudah ada di } \\
\text { dalam } \\
\text { database }\end{array}$ & $\begin{array}{c}\text { Data berhasil di edit } \\
\text { dan disimpan di } \\
\text { database }\end{array}$ & Sesuai \\
\hline $\begin{array}{l}\text { Halaman } \\
\text { hapus data } \\
\text { zona dan } \\
\text { tipologi }\end{array}$ & $\begin{array}{l}\text { Menghapus } \\
\text { data zona dan } \\
\text { tipologi di } \\
\text { dalam } \\
\text { database }\end{array}$ & $\begin{array}{l}\text { Data berhasil di hapus } \\
\text { di dalam database }\end{array}$ & Sesuai \\
\hline
\end{tabular}


Pengujian fusngsional sistem pada tabel user dan admin menggunakan metode Black-Box untuk menemukan kesalahan pada sistem yang sudah dibuat. Pengujian dilakukan menggunakan beberapa web browser apakah sistem dapat berjalan pada browser tersebut diantaranya Google Chrome Versi 83.0.4103.97, Mozila Firefox Versi 77.0.1 dan Microsoft Edge Versi 44.18362.449.0. Hasil dari pengujian sistem menggunakan metode Black-Box berjalan sesuai dengan apa yang di harapkan dengan tingkat keberhasilan 100\% sesuai dengan sistem yang telah dibuat.

\section{KESIMPULAN DAN SARAN \\ 5.1 Kesimpulan}

Berdasarkan hasil dari perancangan dan implementasi rancang bangun sistem informasi geografis pemetaan zona ruang rawan bencana Kota Palu berbasis web maka dapat diambil beberapa kesimpulan yaitu :

1. Berdasarkan hasil dari pengujian fungsional menggunakan metode Black Box sistem informasi geografis pemetaan zona ruang rawan bencana Kota Palu diperoleh 100\% fungsi dan fitur yang terdapat pada sistem dapat berjalan sesuai dengan apa yang telah diharapkan.

2. Berdasarkan hasil pembuatan website sistem informasi geografis pemetaan zona ruang rawan bencana Kota Palu dapat membantu memberikan informasi daerah rawan bencana dan lokasi titik-titik bencana sesuai dengan kriteria yang sudah ditetapkan oleh pemerintah agar masyarakat dapat membangun bangunan sesuai dengan standar SNI.

3. Berdasarkan hasil uji user untuk webgis menunjukan bahwa sistem telah berjalan dengan baik dan mudah digunakan oleh user seperti hasil pengujian berikut bahwa $0.0 \%$ pengguna memilih sangat tidak setuju (STS), $0.0 \%$ pengguna memilih tidak setuju (TS), 9.7\% pengguna memilih netral, $56.6 \%$ pengguna memilih setuju (S), dan $33.7 \%$ pengguna memilih sangat setuju (SS).

\subsection{Saran}

Agar dalam aplikasi ini berjalan dengan baik kedepannya, maka ada beberapa hal yang perlu dilakukan yaitu sebagai berikut :

1. Pengembangan website sistem informasi geografis pemetaan zona ruang rawan bencana Kota Palu dan data informasi ditambah lebih banyak lagi.

2. Memperluas cakupan area zona pengembangan, zona bersyarat, zona terbatas, zona terlarang, dan titik bencana seperti gerakan tanah $(\mathrm{G})$, liquifaksi (L), sempadan sesar (S), tsunami (T) dan banjir (B) yang terdapat pada Kota, Kabupaten, dan kecamatan yang berada pada provinsi Sulawesi Tengah.

3. Agar mempermudah pengguna yang mengakses website sistem informasi geograafis ini dengan memperbanyak informasi tentang halaman yang diakses agar masyarakat lebih memahami webiste tersebut.

4. Untuk pengembangan berikutnya dapat di buat pada aplikasi berbasis mobile.

\section{DAFTAR PUSTAKA}

[1] Hamdani, H., Permana, S. \& Susetyaningsih, A., 2014. ANALISA DAERAH RAWAN BANJIR MENGGUNAKAN APLIKASI SISTEM INFORMASI GEOGRAFIS (STUDI KASUS PULAU BANGKA). Jurnal STT-Garut, 12(1), pp. 1-13.

[2] Wibowo, S. A., Rokhman, M. M. \& Pranoto, Y. A., 2016. APLIKASI PEMETAAN BERBASIS WEBSITE UNTUK PUSAT KESEHATAN MASYARAKAT DI WILAYAH KABUPATEN MALANG. Aplikasi Pemetaan Berbasis Website Suryo, pp. 26-32.

[3] Habibi, M. F., 2018. RANCANG BANGUN SISTEM MONITORING DETEKSI DINI UNTUK KAWASAN RAWAN BANJIR BERBASIS ARDUINO. JATI (Jurnal Mahasiswa Teknik Informatika), 2(2), pp. 190195.

[4] Pradana, A. S. P., 2019. SISTEM INFORMASI GEOGRAFIS PENGGUNAAN LAHAN DAN PRODUKSI TANAMAN PANGAN KABUPATEN KEDIRI JAWA TIMUR. JATI (Jurnal Mahasiswa Teknik Informatika), 3(2), pp. 9-15.

[5] Arbina, M., 2019. SISTEM INFOMASI GEOGRAFIS PEMETAAN DAERAH PERKEBUNAN DAN KOMODITAS HASIL PANEN PROVINSI KALIMANTAN TENGAH. JATI (Jurnal Mahasiswa Teknik Informatika), 3(1), pp. 165-172.

[6] Irwansyah, E., 2013. Sistem Informasi Geografis : Prinsip Dasar dan Pengembangan Apliakasi. Yogyakarta: Digibooks.

[7] Umura. 2012. Quantum GIS. Bandung [08 Agustus 2017]

[8] Agafonkin, V., $2019 . \quad$ leaflet. Tersedia di: https://leafletjs.com/index.html [Diakses pada tanggal 20 Maret 2020].

[9] Herawati, E., 2018. Business Law. Tersedia di: https://business-

law.binus.ac.id/2018/12/31/ketentuan-penataanruang-terkait-wilayah-potensi-bencana/ [Diakses 15 Juni 2020]. 